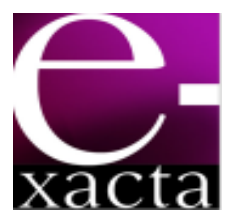

ISSN: 1984-3151

\section{UMWELTS E NICHOS ECOLÓGICOS: MELODIAS E COMUNICABILIDADE DE INTERFACES SEGUNDO A ENGENHARIA SEMIÓTICA}

\author{
UMWELTS AND ECOLOGICAL NICHES: MELODIES AND
} COMMUNICABILITY OF INTERFACES ACCORDING TO THE SEMIOTIC

\author{
ENGINEERING
}

\author{
Natália Moura P. Cortez
}

Doutoranda do Programa de Pós-Graduação em Comunicação Social da UFMG. Belo Horizonte. MG. nmpcortez@gmail.com.

Recebido em: 20/10/2012 - Aprovado em: 20/11/2012 - Disponibilizado em: 30/11/2012

\begin{abstract}
RESUMO: Este trabalho parte da apresentação do conceito de Umwelt de Jakob Von Uexküll e propõe uma relação entre ele, apresentado no âmbito da Biossemiótica, com as noções de Schutz (apud CORREIA,2005) e Mead (1998) acerca desse mesmo conceito, ressaltando-se os pontos de convergência entre as concepções desses autores e suas relações com a Teoria da Percepção de Peirce (2008). Depois de apresentar e discutir o conceito de Umwelt, ele é relacionado ao conceito de nicho na ecologia da percepção, e a relação Umwelt-Nicho é problematizada como uma relação comunicativa entre designers de interfaces e usuários, nos termos definidos pela Engenharia Semiótica. Propõe-se associar a comunicação entre designers e usuários aos correlatos do processo de semiose, identificando a metacomunicação do designer, que visa melhorar os processos de interpretação do usuário, abordada na Engenharia Semiótica, como uma estratégia de cooperação textual entre leitor e autor, discutida por Eco (2011).
\end{abstract}

PALAVRAS-CHAVE: Umwelt. Design de interação. Comunicabilidade. Interface.

ABSTRACT: This paper presents the Jakob von Uexküll's concept of Umwelt and proposes a relationship between it, proposed under the Biosemiotics ambit, and Schutz (1987) and Mead (1998) notions about this same concept, highlighting the points of convergence between the views of these authors and the Peirce's Theory of Perception. After presenting and discussing the concept of Umwelt, it is related to the concept of niche in the ecology of perception, and the relationship Umwelt and niche is problematized in terms of a communicative relationship between designers and interfaces users, as defined by the Semiotic Engineering. It is proposed to connect the communication between designers and users to the semiosis process correlates, identifying the designer's metacommunication, which aims to improve the processes of interpretation of the user, as discussed by the Semiotic Engineering, as a strategy of textual cooperation between reader and author, how Eco (2011) describes. KEYWORDS: Umwelt. Interaction design. Communicability. Interface.

\section{INTRODUÇÃo}

Este trabalho propõe a apresentação do conceito de Umwelt, de Jakob Von Uexküll, destacando, inicialmente, os subconceitos que se articulam organicamente para formá-lo, como o processo vital, que tem dois aspectos importantes, o código e o contexto, a categoria do tempo, que também determina esse processo, e o Círculo Funcional. Depois da apresentação da Umwelt dentro das bases conceituais da Biossemiótica, serão apresentadas as noções de Schutz (1987) e Mead (1998) acerca desse mesmo conceito, com o propósito de evidenciar sua contribuição para a Biossemiótica e seus pontos de 
convergência com a Teoria da Percepção de Peirce (2008).

O conceito de Umwelt, dentro da ecologia da percepção, será relacionado ao conceito de nicho, e o design de interação é problematizado com base no uso dessas metáforas biológicas, observando os Umwelts como traços dos sistemas perceptivos dos usuários e os nichos como ambientes criados a partir de sistemas computacionais, onde os usuários interagem.

Os designers dos sistemas computacionais e os usuários se engajam em relações comunicativas, e o design de interação tem como uma de suas metas, ou princípio de qualidade, a comunicabilidade de interfaces. A partir da apresentação da Engenharia Semiótica, que define métodos de avaliação da comunicabilidade de interfaces, propõe-se pensar a comunicação entre designers e usuários por meio dos conceitos de Umwelt e nicho da ecologia da percepção associados aos correlatos do processo de semiose de Peirce (2008), identificando a metacomunicação do designer como uma estratégia de cooperação textual, como discute Eco (2011).

\section{SOBRE A NOÇÃo dE UMWELT}

A premissa epistemológica da teoria sistêmica de Jakob Von Uexküll implica no entendimento do processo vital como um sistema coerente em que indivíduo e ambiente estão inter-relacionados, constituindo um todo maior. Nessas bases, Jakob Von Uexküll (apud UEXKÜLL, 2012, p. 22), enfatizando as interações entre indivíduo e ambiente e sua afetação recíproca, apresenta o conceito de Umwelt como o segmento ambiental definido pelas capacidades receptoras e efetoras específicas de uma espécie.

De acordo com a interpretação de Queiroz (2012), Jakob von Uexküll define o conceito de Umwelt como o mundo dos fenômenos sensórios e seus efeitos, o que é específico de cada espécie biológica. Segundo esse autor, o Umwelt pode ser concebido como o mundo semiótico dos organismos, ou o aspecto fenomenal do ambiente, selecionado pelo equipamento sensório-motor da espécie.

Santaella (2012), ao discutir o conceito de Umwelt dentro da ecologia da percepção, considera que o Umwelt se encontra em cada órgão do corpo de um organismo e ao mesmo tempo em sua constituição geral. Segundo a autora

\begin{abstract}
Os animais superiores, graças ao sistema nervoso central, possuem um mapa interior representativo do ambiente circundante, o que facilita a abertura do Umwelt. Assim, animais superiores têm órgãos sensórios capazes de se mover, o que lhes permite explorar o mundo ativamente. (SANTAELLA, 2012, p.22)
\end{abstract}

Como parte do conceito de Umwelt, Uexküll (2012) descreve as relações entre os elementos do processo sígnico como um sistema dinâmico organizado em forma de círculo. O "Círculo Funcional" (functional circle [Funktionskreis]) foi concebido por Jakob Von Uexküll a fim de interpretar processos sígnicos em organismos medindo sua duração. A marcação dos processos sígnicos procede de um modo específico em cada espécie, como pode ser observado pelo comportamento dos diferentes receptores e efetores (na terminologia de Uexküll "órgão perceptivo" (Merkorgan, Rezeptor) e "órgão operacional" (Wirkorgan, Effektor). Nas palavras do autor:

O círculo funcional pode ser descrito como um modelo para a contagem segundo o qual os animais integram seus automundos compostos de sinais e portadores sígnicos, recebidos de seu ambiente (environment [Umgebung]), com os sistemas em que seus organismos funcionam como subsistemas. A melodia da contagem do círculo funcional tem quatro compassos: signo perceptivo, pista perceptiva, signo operacional e pista operacional. Assim um novo verso começa com um novo signo perceptivo continuando a melodia (ou o texto) com os mesmos quatro compassos. (UEXKÜLL, 2012, p.35)

Segundo Uexküll (2012), os processos sígnicos dependem da existência de um código no indivíduo que possa ser descrito como um sistema de signos 
operacionais (operational signs [Wirkzeichen]), no decorrer do qual o "objeto semiótico" é formado pelos signos perceptivos. Os signos do código do indivíduo correspondem a certos processos do ambiente, e relacionam-se. O contexto que desencadeia a melodia do Umwelt é entendido por Jakob Von Uexküll como um nicho, que, por sua vez, corresponde a uma seção da natureza que provê os recursos essenciais para uma espécie sobreviver e ter condições de se reproduzir.

Além do código, que representa o repertório dos signos disponíveis para o indivíduo, Jakob Von Uexküll (apud UEXKÜLL, 2012) afirma que há uma sequência fixa por meio da qual os signos são encadeados. Para que a semiose ocorra, é essencial que a sequência permaneça inalterada. Segundo o autor, os signos devem ser arranjados como um "texto", com o propósito de se tornarem definitivamente signos para o indivíduo.

O texto do indivíduo está relacionado ao contexto de certas ocorrências no meio circundante: o signo perceptivo, relacionado ao contexto do surgimento do objeto semiótico, desencadeia processos sígnicos sucessivos. Por isso, o contexto deve ser produzido pelo ambiente para o texto ser recitado, que segundo o autor, representa a "contrapartida objetiva" ao universo subjetivo do indivíduo.

Como aponta Queiroz (2012), as relações entre Signo e Umwelt, nicho cognitivo, e outras, vêm sendo pesquisadas por diversos autores que investigam temáticas relacionadas à Biossemiótica e à Interação Humano-Computador. Além disso, o autor destaca que o conceito de Umwelt tem grandes precursores, como Schutz e Mead (1998), que contribuíram decisivamente para a construção da Biossemiótica. $\mathrm{Na}$ teoria de Schtuz (apud CORREIA, 2005), o conceito de Umwelt é definido como um dos quatro submundos que fazem parte do mundo social e que se organizam a partir da experiência partilhada do tempo e do espaço.

Segundo o autor, o mundo social divide-se da seguinte forma: o mundo dos consociados (Umwelt); o mundo dos contemporâneos (Mitwelt); o mundo dos predecessores (Vorwelt) e o mundo dos sucessores (Folgewelt). O Umwelt é o mundo social em que se encontra diretamente a presença dos outros como coassociados (Miltmenschen), isto é, nessa situação partilha-se o contexto temporal e espacial do aquiagora. Só na "orientação-para-nós" (Wirkenbeziehung; We-orientation), segundo o autor, é possível ter a presença corporal do outro no encontro face a face. No Mitwelt, que é organizado em termos de "orientação-para-eles" (Ihrbeziehung; Theyorientation), não há experiência direta ou imediata com os contemporâneos (Nebmenschen), mas eles são compreendidos como abstratos ou anônimos. O Vorwelt e o Folgewelt representam, respectivamente, o caráter de passado e de futuro.

O conceito de Umwelt apresentado por Shutz (apud CORREIA, 2005) relaciona-se à comunicação entre interlocutores que compartilham o mesmo contexto de co-presença, ou uma comunidade de tempo e uma comunidade de espaço, como prefere o autor. Segundo ele, a situação face a face pressupõe uma efetiva simultaneidade entre duas correntes de consciência. Numa primeira fase, no Umwelt, pode verificar-se a "orientação-para-o-tu"(Thou-orientation) que é a forma pura da tomada de consciência da existência de outro ser humano, além de si próprio, percebido como uma pessoa. Entretanto, o fato de que apenas um indivíduo perceba o outro como semelhante não significa que o outro indivíduo fará o mesmo, como discute Schutz (1967, p. 162-164 apud CORREIA, 2005). Apenas quando a orientação é recíproca pode surgir o relacionamento de "Nós" (Werelation) que, enquanto permanece intacto, permite 
abertura e torna acessíveis os atos intencionais um do outro.

Para Mead (apud SEVILLA, 2012), o conceito de Umwelt está relacionado à consciência. Segundo o autor, o indivíduo adquire consciência quando desenvolve habilidades, ou seja, traços que indicam termos evolutivos quando ele passa de um Umwelt a outro. A aquisição mental (informações, conhecimento) revela a consciência que emerge por meio das ações de seletividade do próprio indivíduo, capaz de se referir a si e a um objeto entre outros, utilizar as experiências em referência aos Umwelts anteriores e comunicar os significados de todas estas interações a si mesmo, bem como para os outros. Mas, segundo o autor, há diferenças na capacidade de extrair sentido dos diferentes Umwelts. Tudo depende da evolução do indivíduo e de sua capacidade de comunicação dos sentidos, bem como do grau de imersão, proporcionado em cada ambiente, e a facilidade com que o indivíduo transita entre um Umwelt e outro. Para Mead (apud SEVILLA 2012), a consciência é uma semiose (em grande escala) de respostas e reações existenciais que se tornam significativas. $O$ autor destaca $O$ senso de historicidade desse processo, e que, segundo ele, a experiência do tempo tem uma profunda influência sobre a experiência do indivíduo no mundo.

\section{Texto e Contexto: A melodia do UmWelt E O NICHO}

$\mathrm{Na}$ leitura de Merleau-Ponty (apud SANTAELLA, 2012, p. 44), "umwelt é uma melodia que canta a si mesma". A melodia a ser "tocada" representa o texto a ser recitado como apresentou Jakon Von Uexküll. Esse autor não entendia o Umwelt como apenas um ambiente biológico do indivíduo, mas como seu campo perceptivo específico, a esfera de sua interação prática, como relata Queiroz (2012). Segundo esse autor, deve-se distinguir o conceito de Umwelt do de habitat e do nicho ecológico, sendo que o primeiro refere-se ao habitat objetivo do organismo, externo a ele, e o nicho, que se refere à função ecológica da espécie em um ecossistema. Umwelt, por sua vez, relaciona-se ao mundo "experenciado" pelo organismo.

Gibson (1986, p.128 apud SANTAELLA, 2012, p.55) afirma que o nicho se refere mais ao modo como o organismo vive do que onde ele vive. Esse autor também sugere que um nicho é um conjunto de affordances. A percepção implica um ambiente significativo revelando-se para o percebedor que o contempla. Segundo Santaella (2012), as affordances não são fenomênicas, nem mentais, não são intrínsecas, nem absolutas, mas fatos ecológicos pertencentes ao ambiente relacionado ao indivíduo.

O termo affordance é utilizado no âmbito da interação humano-computador e nas teorias do design de interface para indicar um atributo de um objeto para que se saiba como utilizá-lo, manipulá-lo, como discute Preece (2005). Segundo Norman (1988 apud PREECE, 2005), affordance significa dar uma pista, ou seja, revelar características que mostrem as operações e manipulações que podem ser feitas com um objeto, sendo uma boa estratégia para criar interfaces amigáveis no design de interação. Sendo que o nicho se refere à função ecológica ou o modo de vida da espécie em um ecossistema e Umwelt relaciona-se com o mundo percebido pelo organismo em interação com 0 ambiente. Os ambientes sociocomunicacionais criados a partir de sistemas computacionais podem ser observados como nichos e as maneiras de interagir dos internautas como expressões dos Umwelts.

O conceito de Umwelt, entendido como mundo semiótico dos organismos, pode servir como lente para observação das interações nos ambientes sociomunicacionais diversos, conformados a partir de 
diferentes tipos e aplicações computacionais, sejam websites, softwares, etc. Os indivíduos, que conseguem transitar bem entre diferentes Umwelts, como destacou Mead (apud SEVILLA, 2012), são favorecidos no contexto de convergência de fluxos comunicacionais. Jenkins (2008) ressalta a dimensão cognitiva da convergência a partir do ponto de vista dos usuários das tecnologias, que devem se adaptar de um modo de uso para outro, de uma ambiência para outra, conforme o dispositivo de comunicação utilizado.

Segundo Uexküll (2012), os órgãos perceptivos projetam pistas perceptivas, indicando objetos do ambiente que, dessa maneira, ganham significado. A partir disso, os objetos podem ser identificados pelas “pistas operacionais", que podem ser relacionadas às affordances nos nichos. Os usuários e os designers de sistemas se engajam em interações comunicativas, que requerem esforços de ambas as partes para otimização da representação e da interpretação das mensagens, registradas nas interfaces. Como todo "texto" deve ser atualizado pelo "destinatário", conforme Eco (2011), as interfaces devem ser alvo dos esforços de compreensão das mensagens por parte dos usuários, que são seus destinatários. Da mesma forma, as intenções comunicativas, representadas no texto da interface, são concebidas a partir da ideia de que o designer (emitente) faz do modelo mental do usuário, o que envolve suas capacidades perceptivas, cognitivas, e outras.

Para Eco (2011), em razão da natureza incompleta dos textos, uma expressão depende de ser correlacionada com referência a um determinado código, ao seu conteúdo convencionado. Nesse sentido, segundo o autor, o destinatário é sempre postulado como o operador que seja capaz de compreender o texto, engajando-se nessa atividade que requer seu esforço.
O texto está entremeado de espaços em branco, de interstícios a serem preenchidos, e quem o emitiu previa que esses espaços e interstícios seriam preenchidos, e os deixou brancos por suas razões. Antes de tudo, porque um texto é um mecanismo preguiçoso, (ou econômico) que vive da valorização de sentido que o destinatário ali introduziu; e somente em casos de extremo formalismo, de extrema preocupação didática ou de extrema repressividade 0 texto se complica com redundâncias e especificações ulteriores. (ECO, 2011, p.37)

De acordo com o autor, um texto postula o próprio destinatário, uma vez que é emitido por alguém e necessita que outro alguém o atualize, mas a existência concreta e empírica desse alguém pode não ser querida nem esperada. Para Eco (2011), tanto o emitente, quanto o destinatário, são gramaticalmente manifestados pela mensagem, o mesmo ocorre em relação à interface e os designers e usuários. Os designers de interface, como produtores de informação, utilizam sistemas sígnicos para representar as informações pretendidas de modo a alcançar um objetivo (intenção). Existe um mapeamento que conecta as ações, que o sistema está apto a executar, representadas também numa linguagem binária, e os sistemas sígnicos eleitos pelos designers para se referir a essas ações. A codificação é linguística, ou seja, o mapeamento se faz por meio de signos verbais, visuais etc, na linguagem do usuário, chamada "natural", conectada a linguagem binária de programação.

A interface funciona como signo no processo de comunicação entre designer e usuário, pois, uma vez que realiza a mediação entre ambos, é determinada pelo objeto nas relações de representação e determina 0 interpretante nas relações de interpretação. Como ocupa o lugar lógico do signo na cadeia semiósica, a interface pode ser pensada como uma membrana que, de um lado, tem suas inscrições em linguagem natural e, no outro, as inscrições são zeros ou uns. 
Colocada a relação entre usuários e designers como um processo sígnico nos moldes do modelo lógico Peirceano, por analogia, pode-se também dizer que as interfaces serão mais amigáveis nas situações em que os designers projetarem nichos que façam tocar a melodia dos Umwelts, ou seja, que favoreçam os mecanismos de percepção dos usuários. Em função desses argumentos, julga-se necessária a recuperação das temáticas centrais abordadas pela Teoria da Percepção formulada por Peirce (2008), bem como seus pontos de intercessão com os pensamentos de Schutz (1987) e Mead (1998).

\section{DA teoria dA PERCEPÇÃo PEIRCEANA À COMUNICABILIDADE DE INTERFACES}

Assim como Mead (1998) e Schutz (1987), Peirce elaborou sua teoria da percepção sob a dominância da secundidade. A consciência a que Mead (apud SEVILLA, 2012) se refere é posterior ao Umwelt, equivalendo-se, assim, à segunda categoria fenomenológica de Peirce, " (...) a categoria do confronto, da ação e reação, da interação (...)", como destaca Santaella (1993, p.15). Da mesma maneira, o conceito de Umwelt de Schutz (apud CORREIA, 2005) relaciona-se à situação de comunicação entre interlocutores que compartilham o mesmo contexto de co-presença, no qual a situação face a face pressupõe uma efetiva simultaneidade entre duas correntes de consciência, como discute o autor.

Para que a relação estabelecida entre o conceito de Umwelt e sua relação com a Teoria da Percepção de Peirce fique mais clara, faz-se necessário retomar brevemente os pontos centrais da Teoria Semiótica de Peirce (2008). Esse autor entendia a Semiótica como uma filosofia dos signos, sendo que gestos, ideias e cognições são considerados entidades semióticas. O autor construiu um complexo categorial buscando estabelecer categorias de análise dos fenômenos que tivessem um caráter mais universal, o que, segundo ele, tornaria possível compreender o mundo em sua totalidade, daí a necessidade do desenvolvimento de um sistema com categorias capazes de abarcar aspectos do conhecimento e da cognição. Dessa forma, pode-se entender a perspectiva semiótica de Peirce (2008) como uma filosofia do conhecimento.

Assim foi desenvolvida a tríade de categorias universais que dizem da percepção dos fenômenos do mundo: Firstness (Primeiridade), Secondness (Secundidade) e Thirdness (Terceiridade). A Primeiridade corresponde ao sentimento imediato e sem reflexão presente nas coisas, relaciona-se à qualidade. A Secundidade determina ação e reação, é a categoria da relação, e a Terceiridade, por sua vez, é a categoria da mediação, que tem por função relacionar um segundo a um terceiro, por meio de síntese intelectual. Refere-se à inteligibilidade do pensamento em signos. Essa categoria fenomenológica de crescimento contínuo corresponde à definição de signo genuíno como processo relacional triádico que conduz à noção de semiose infinita, como apresenta Santaella (2008). Das várias definições do signo formuladas por Peirce (apud SANTAELLA, 2008, p.12), destaca-se a seguinte, com o propósito de dar continuidade à linha de pensamento proposta:

\begin{abstract}
Um signo, ou representamen, é aquilo que, sob certo aspecto ou modo, representa algo para alguém. Dirige-se a alguém, isto é, cria na mente dessa pessoa, um signo equivalente, ou talvez um signo mais desenvolvido. Ao signo assim criado, denomino interpretante do primeiro signo. O signo representa alguma coisa, seu objeto. Representa esse objeto não em todos os seus aspectos, mas com referência a um tipo de ideia que eu, por vezes, denominei fundamento ou representamen. (SANTAELLA, 2008, p.12).
\end{abstract}

Dentro da moldura lógica da semiose, Peirce (apud SANTAELLA, 1993) concebe a percepção como um processo sígnico, ou seja, como uma semiose da percepção. Na tríade da semiose, o juízo perceptivo assume o lugar de signo, o objeto dinâmico (que se 
refere à realidade e determina a representação do signo) refere-se ao percepto, o objeto imediato (objeto tal qual como o signo o representa) ao percipuum, e o interpretante refere-se à asseveração do juízo perceptivo. Segundo Peirce (apud SANTAELLA, 1993, 2012), o percepto é aquilo que tem realidade própria e está fora de nossa consciência, sendo apreendido pelo ato perceptivo, e o percipuum é o percepto tal como ele é imediatamente interpretado no julgamento da percepção.

Mas, para compreender os processos de comunicação entre designers e usuários por meio das interfaces computacionais, os três correlatos do processo sígnico podem ser organizados também da seguinte forma: $A$ interface, que faz a mediação entre o objeto (designer e suas intenções comunicativas) e o interpretante, lugar lógico da cadeia semiótica ocupado pelo usuário, (que interpreta as intenções comunicativas do designer materializadas na interface), ocupa o lugar lógico do signo. Ou seja, a interface, sendo signo, conecta o designer e o usuário, objeto e interpretante da cadeia semiósica. O signo (interface) é determinado pelo objeto (designer e suas intenções comunicativas) porque representa o objeto de forma que os usuários, ou intérpretes, possam interpretar as intenções comunicativas do designer gerando o signo interpretante, como revela a Figura 1.

Essa organização dos correlatos da semiose remete ao conceito de comunicabilidade, refletindo as bases teóricas e conceituais da Engenharia Semiótica, que concebe a interação humano-computador como comunicação humana mediada por sistemas computacionais, conforme (DE SOUZA, 2009). A comunicabilidade é abordada como um critério de qualidade nos estudos da interação humanocomputador, assim como a usabilidade (que se relaciona à facilidade de aprendizado e uso dos sistemas, e a satisfação em usá-los) e a acessibilidade (que se ocupa da remoção de barreiras que impedem a interação e o acesso à interface).

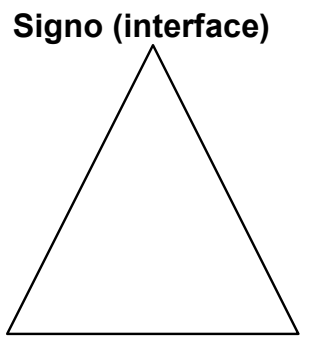

\section{Objeto (designer) Interpretante (usuário)}

Figura 1. Cadeia semiósica e relações de comunicabilidade de interfaces

Segundo a Engenharia Semiótica, a comunicabilidade refere-se à capacidade do designer do artefato interativo (sistema) de comunicar ao usuário suas intenções de design e a lógica que rege a interface. $O$ foco principal da Engenharia Semiótica, segundo De Souza (2009), é pensar maneiras eficientes por meio das quais os designers consigam comunicar o que acontece do seu lado da relação e expliquem como criaram o sistema com base no que pensam sobre as expectativas dos usuários. A interação humanocomputador é percebida como uma instância de metacomunicação, uma vez que a interface de um sistema informa ao usuário sobre como ele pode ou deve usá-la, por que usá-la e com que efeitos a cada ação, como argumenta De Souza (2009). O conteúdo essencial dessa mensagem pode ser parafraseado, gerando um modelo genérico e resumido, denominado de modelo de metacomunicação, ou paráfrase da metamensagem, por meio da qual, segundo De Souza (2009, p.16), os designers se comunicam com os usuários. A metamensagem consiste no seguinte:

Esse é meu entendimento de quem você é, do que aprendi que você quer ou precisa fazer, de que forma e por que. Esse é o sistema que projetei para você, e essa é a melhor forma como você pode ou deve usá-lo para alcançar uma gama de objetivos que se encaixam nesta visão. (De Souza, 2009, p.16) 
Como o designer não pode estar fisicamente presente durante o processo de interação, a Engenharia Semiótica considera que o sistema "entrega" as mensagens do designer ao usuário, ele funciona como seu preposto. Segundo a autora, o discurso do sistema computacional é uma versão de uma conversação entre o designer e o usuário com o propósito de atingir a intenção comunicativa final. Mas, as interpretações dos signos nas interfaces realizadas pelo sistema, ao contrário da interpretação dos usuários e dos designers, é determinada por relações causais de um programa de computador, com procedimentos e funções organizados a priori, que determinam os mesmo tipos de elementos de significação. Por isso, considera-se que a semiose é interrompida para que os processos de avaliação se realizem.

A Engenharia Semiótica propõe dois métodos de avaliação de interfaces: um método de inspeção - O Método de Inspeção Semiótica - e um método de observação, que envolve testes com usuários - A Avaliação de Comunicabilidade. O Método de Inspeção Semiótica avalia a qualidade da emissão da metacomunicação do designer. A aplicação desse método prevê a inspeção da interface por especialistas, incluindo a documentação disponível para o usuário (ajuda, manual de uso) e a interpretação dos signos codificados com o objetivo de reconstruir a metamensagem, considerando perfis de usuário, cenários de interação e outros.

A inspeção semiótica avalia a qualidade da emissão da metacomunicação do designer, enquanto que a avaliação de comunicabilidade estima a qualidade da recepção dessa metacomunicação, buscando conhecer e compreender os processos de interpretação dos usuários, intenções e rupturas de comunicação. Os designers de interface, como produtores de informação, utilizam sistemas sígnicos para representar suas intenções comunicativas com vistas à interpretação do usuário. A metacomunicação avalia a qualidade da emissão e da recepção das mensagens, conforme o método utilizado. Pode-se dizer então que a metacomunicação conforma estratégias textuais para leitura dos textos das interfaces por meio de seus leitores (usuários) e autores (designers). Como diz Eco (2001), a própria mensagem já postula seus emitentes e destinatários, e a metacomunicação, ao fazer isso, parece contribuir para que os espaços em branco, os interstícios do texto, como coloca Eco (2011) sejam atualizados.

O leitor-usuário deve esforçar-se para interpretar o texto, que, em sua essência, é incompleto, como mostrou Eco (2001). Autor e leitor são estratégias textuais e o autor também pode ser entendido como hipótese interpretativa do leitor, uma vez que a cooperação textual se realiza entre duas estratégias discursivas e não entre dois sujeitos, como discute Eco (2011).

O autor empírico, sujeito da enunciação textual, forma uma hipótese de Leitor Modelo, segundo Eco (2011) e, ao traduzi-la como própria estratégia, configura-se a si mesmo como autor. Do outro lado da relação, o leitor empírico, definido como sujeito concreto da cooperação, deve configurar para si próprio a hipótese de autor, que é deduzida da estratégia textual.

A comunicabilidade das interfaces é analisada por meio da metamensagem emitida, quando a interface é inspecionada e verifica-se se as intenções comunicativas do designer são claras, ou seja, se o usuário consegue interpretá-las, e quando a metamensagem é recebida pelos usuários de fato, que são submetidos a testes controlados. Por isso a Engenharia Semiótica apresenta um método de inspeção de interfaces - Método de Inspeção Semiótica - que indica resultados potenciais, inferidos a partir de investigações de especialistas, e um método de observação - que fornece dados reais, uma 
vez que os próprios usuários são testados e suas percepções avaliadas.

Assim como nas estratégias textuais apresentadas por Eco (2011), a metacomunicação representa o ponto de encontro entre duas relações do processo comunicativo, que têm o propósito comum de tornar a comunicação fluida, geradora de sentido. A metacomunicação melhora a compreensão do usuário, aprimorando suas habilidades para a cooperação textual, ao mesmo tempo em que mostra a ele um pouco do designer, de como ele o vê e como pensa. O designer, por sua vez, que cria para um modelo de usuário, um usuário-modelo, mostra-se ao usuário empírico como autor-modelo-designer por meio de sua estratégia textual.

Essa relação é a mesma entre o nicho e suas affordances, o que faz tocar a música da Umwelt e desencadeia o processo de semiose, e do Umwelt, que além de ser uma melodia que canta a si mesma, constitui-se também em correlação sistêmica com o nicho que a abriga, orientando as formas que desencadeiam o tocar da música.

Ou seja, os nichos (ambientes sociocomunicacionais gerados pelos sistemas) são criados levando em conta as percepções e cognições dos usuários ao mesmo tempo em que os usuários aprendem a interagir nos ambientes, e geram, ao longo do tempo, hábitos que conformam padrões ou convenções para o design de interação. Assim, o texto configura o contexto que faz recitar o texto, e, o Umwelt, de diversas formas, determina o nicho que desencadeia sua própria música.

\section{REFERÊNCIAS}

CORREIA, J. C. A teoria da comunicação de Alfred Schutz. Lisboa: Horizonte, 2005.

DE SOUZA, Clarisse. Semiotic Enginnering Methods for Scientific Research in HCl.Clarisse Sieckenius de Souza and Carla Faria Leitao. Morgan \& Claypool Publishers, 2009.

ECO, Humberto. Lector in fabula: a cooperação interpretativa nos textos narrativos. São Paulo: Perspectiva, 2011.

JENKINS, Henry. Cultura da Convergência. São Paulo: Editora Aleph, 2008.

MEAD, George H. Espiritu, persona y sociedad: Desde el punto de vista del conductismo social. México: Paidós, 1993.

PEIRCE, C. S. Semiótica. São Paulo: Perspectiva, 2008.

PREECE, Jennifer. Design de interação: além da interação homem-computador. Jennifer Preece,
Ivone Rogers e Helen Sharp; trad. Viviane Possamai. Porto Alegre: Bookman, 2005.

QUEIROZ, Sistemas semióticos, artefatos cognitivos, Umwelt - uma contribuição ao Design da Informação. Disponível em: $<$ http://www.infodesign.org.br/conteudo/artigos/432/in g/ID v7 n2 $2010 \quad 07 \quad 12$ Queiroz.pdf>. Acesso em: jul. 2012

SANTAELLA, L. A percepção: uma teoria semiótica. São Paulo: Experimento, 1993. 120p.

SANTAELLA, L. A Teoria Geral dos signos: com as linguagens significam as coisas. São

Paulo: Cengage Learning, 2008.

SANTAELLA, L. Percepção: fenomenologia, ecologia, semiótica. São Paulo: Cengage Learning, 2012.

SEVILLA, J. C. The Realm of Continued Emergence":The Semiotics of George Herbert Mead and Its Implications to Biosemiotics, 
Semiotic Matrix Theory, and Ecological Ethics. Disponível

media.wix.com/.../257b796cfb886748c359aca9.

Acesso em: jul.2012
UEXKÜLL, Thure Von. A teoria da Umwelt de Jakob von Uexküll. Disponível em: $<$ revistas.pucsp.br/index.php/galaxia/article/download /1369/852>. Acesso em: jul.2012 